\title{
THE EFFECT OF THE ADDITION OF ACTIVATED CHARCOAL TO DIFFERENT FORMULATIONS OF CALCIUM HYDROXIDE ON THEIR EFFECT ON THE FRACTURE RESISTANCE OF ENDODONTICALLY TREATED TEETH
}

\author{
Medhat Taha Elfaramawy*
}

\begin{abstract}
This study aimed to evaluate the effect of the addition of the activated charcoal to different formulations of calcium hydroxide on the fracture resistance of endodontically treated teeth. Ninety one freshly human extracted single rooted teeth were selected. The samples were cleaned and shaped and classified according to the type of the dressing into five groups; Group 1; (21 samples) dressed with calcium hydroxide paste with Iodoform (Metapex) (META, Chungcheongbuk-do, Korea), Group 2; (21 samples) dressed with conventional calcium hydroxide with saline (GAMA dental lab, Cairo, Egypt). Group 3; (21 samples) dressed with calcium hydroxide paste with Iodoform mixed with activated charcoal (Eucarbon Sedico, Cairo, Egypt) and Group 4; (21 samples) dressed with conventional calcium hydroxide and activated charcoal with saline and Group 5; Control group (undressed). The samples were further classified according to the observation time into: Subgroup A; (7 samples) after two weeks. Subgroup B; (7 samples) after one month and Subgroup C; (7 samples) after two months. Samples were loaded vertically after the observation periods using Universal Testing Machine until fracture. The results showed that the fracture resistance of the samples dressed with either Metapex or conventional calcium hydroxide showed lower resistance to fracture than those dressed with either two formulations with activated charcoal. It was concluded that the addition of activated charcoal to the calcium hydroxide compounds can decrease their weakening effect on the endodontically treated teeth.
\end{abstract}

\section{INTRODUCTION}

The use of calcium hydroxide in the treatment of infected canals is considered mandatory in certain refractory cases because of its action against specific bacterial species that cannot be eradicated with conventional cleaning and shaping ${ }^{(1,2)}$ its antibacterial action is gained via the release of hydroxyl ions that give it strong alkaline properties $^{(3)}$. However this strong alkalinity has a detrimental effect on the dentinal proteinic structure which causes weakening of the root canal dentine ${ }^{(4,5)}$ . This study aimed to evaluate the effect of addition

\footnotetext{
* Associate Professor, Endodontic Department, Faculty of Dentistry, Ain shams University.
} 
of activated charcoal to different formulations of calcium hydroxide on their weakening effect of root canal dentine.

\section{MATERIALS AND METHODS}

Samples Preparation: Ninty one freshly human extracted single rooted teeth inspected under surgical microscope (Seiler, USA) to exclude any cracks or fracture lines. Teeth were decoronated at cement-enamel junction using diamond bur in high speed with air/water coolant. Teeth were stored in saline till used.

Root canal instrumentation: Biomechanical preparation of samples was done in step back manner reaching file \#50 as a master apival file and last file for flaring was \#70. Irrigation of the samples was carried out using sodium hypochlorite $2.5 \%$. and patency of the samples was ensured using file \#10. After dressing of the samples according to its classification the caronal portion was sealed using glass ionomer cement. The samples of the control group were tested without biomechanical preparation.

Samples Classification: Samples were classified according to the type of the dressing into five groups; Group 1; (21 samples) dressed with calcium hydroxide paste with Iodoform (Metapex) (META, Chungcheongbuk-do, Korea), Group 2; (21 samples) dressed with conventional calcium hydroxide with saline (GAMA dental lab, Cairo, Egypt). Group 3; (21 samples) dressed with calcium hydroxide paste with Iodoform mixed with activated charcoal (Eucarbon Sedico, Cairo, Egypt) and Group 4; (21 samples) dressed with conventional calcium hydroxide and activated charcoal with saline and Group 5; Control group (undressed). The samples were further classified according to the observation time into: Subgroup A; (7 samples) after two weeks. Subgroup B; (7 samples) after one month and Subgroup C; (7 samples) after two months.

\section{Mounting of samples}

A plastic syringes $\left(10 \mathrm{~cm}^{3}\right)$ were used to form the sample block which consisted of a tooth imbedded perpendicularly in self-cure acrylic resin.

\section{Method of evaluation}

The samples were mounted on the lower fixed compartment of a Universal Testing Machine (Model LRX-Plus, Lloyd Instruments, Fareham, UK) with a loadcell of $5 \mathrm{kN}$-and secured by tightening screws. Samples were vertically loaded $(1 \mathrm{~mm} / \mathrm{min})$ until fracture occurred. Computer software (Nexygen-MT-4.6; Lloyd Instruments) was used to record the data.

\section{Statistical analysis:}

Data were analyzed using IBM SPSS V23 (IBM, USA) statistical analysis software. ANOVA and Kruskal-Wallis tests were used to compare data in each group. The level of significance was set at 0.05.

\section{RESULTS}

Group 1: (Metapex). The fracture resistance decreased significantly by time as it was $940 \pm 10.5$ after two weeks, $859 \pm 15.2$ after one month and $790 \pm 11$ after two months.

Group 2: Conv. $(\mathrm{Ca}(\mathrm{OH}) 2$. There was significant decrease in the fracture resistance reaching $672 \pm 20$ after two months

Group 3: (Metapex + Activated charcoal). The fracture resistance after two weeks was $960 \pm 14.5$ and decreased significantly by time reaching $850 \pm 16$ after two months.

Group 4: (Conv. $(\mathrm{Ca}(\mathrm{OH}) 2+$ Activated charcoal). The fracture resistance after two weeks was $960 \pm 14$ and decreased significantly by time reaching $832 \pm 20$ after two months.

For all tested groups the average fracture resistance of all samples decreased significantly by time. However the groups with activated charcoal showed significantly higher values of fracture resistance for all tested periods. 
TABLE (1) Fracture resistance (average and standard deviation) of different groups. (N).

\begin{tabular}{|c|c|c|c|c|c|c|}
\hline $\begin{array}{c}\text { Group } \\
\text { Subgroup }\end{array}$ & Metapex & Conv. $\left(\mathrm{Ca}(\mathrm{OH})_{2}\right.$ & $\begin{array}{c}\text { Metapex } \\
+ \text { A.Charc. }\end{array}$ & $\begin{array}{c}\text { Conv. }\left(\mathrm{Ca}(\mathrm{OH})_{2}+\mathrm{A} .\right. \\
\text { Charc. }\end{array}$ & Control & P-value \\
\cline { 1 - 4 } 2 weeks & $940 \pm 10.5$ & $925 \pm 11$ & $960 \pm 14.5$ & $960 \pm 14$ & \multirow{2}{*}{$1021 \pm 18$} & $<0.0001$ \\
\cline { 1 - 4 } One month & $859 \pm 15.2$ & $845 \pm 12$ & $900 \pm 20.1$ & $895 \pm 23$ & $<0.0001$ \\
\cline { 1 - 4 } Two months & $790 \pm 11$ & $672 \pm 20$ & $850 \pm 16$ & $832 \pm 20$ & & $<0.0001$ \\
\hline
\end{tabular}

$P \leq 0.05$ is considered significant.

\section{DISCUSSION}

The main problem of the endodontically treated teeth is the high susceptibility to fracture which may be related to the use of different intra-canal irrigations and medications, large carious lesions, increased brittleness as a result of loss of moisture and the lack of masticatory reflux. Estrella et $\mathrm{al}^{(3)}$ explained the mechanism of action of calcium hydroxide through the ionic dissociation and the release of hydroxyl ions that gives it the strong alkalinity and hence strong antibacterial action and anti-inflammatory action ${ }^{(3,6,7)}$. This antibacterial action is gained through the destruction of bacterial cytoplasmic membrane and the dissociation of the tertiary ionic bond of the bacterial membrane. However this action is not specific and so causes the main disadvantage of calcium hydroxide through the destruction of the ionic bond of the dentinal proteinic structure and so affects the dentine structural integrity ${ }^{(5)}$. The results of this study showed significant decrease in the fracture resistance of all tested groups by time which was in agreement with Andreasen etal ${ }^{(8)}$ and Sogukan and Arikan ${ }^{(10)}$ and against the results of Grigoratos etal ${ }^{(9)}$. This is attributed to the denaturation of the acid proteoglycans of dentine which serves as the main bond between the organic collagen and the inorganic hydroxyapatite crystals and so affects the dentine structural integrity ${ }^{(8)}$. The samples that dressed with calcium hydroxide with the addition activated charcoal showed higher fracture resistance compared to the samples dressed with calcium hydroxide for all tested periods. This may be related to the adsorption properties of the activated charcoal which can slow down the release of hydroxyl ions from the calcium hydroxide compounds and so decrease their effect on the structural integrity of dentine.

\section{CONCLUSION}

The addition of activated charcoal to the calcium hydroxide compounds can decrease their weakening effect on the endodontically treated teeth.

\section{REFERNCES}

1. Baik J.E., Kum K.Y., YunC.H., Lee J.K., LeeK., Kim K.K., and Han S.H.: Calcium Hydroxide Inactivates Lipoteichoic Acid from Enterococcus faecalis. J. Endod., 2008, 1355-9.

2. Khan A.A., Sun X. and Hargreaves K.M.: Effect of calcium hydroxide on proinflammatory cytokines and neuropeptides. J. Endod., 2008, 1360-3.

3. Estrela C., Sydney G.B., Bammann L.L, Junior O.F.: Mechanism of Action of Calcium and Hydroxyl Ions of Calcium Hydroxide on Tissue and Bacteria. Braz. Dent. J. 1995, 85-90,

4. Marending M., Stark W.J., Brunner T.J., Fischer J. Zehnder M. Comparative assessment of time-related bioactive glass and calcium hydroxide effects on mechanical properties of human root dentin. Dent. Traumatol. 2009, 126-9,.

5. Sahebi S, Moazami F. and Abbott P.: The effects of shortterm calcium hydroxide application on the strength of dentine. Dent. Traumatol. 2010, 43-6. 
6. Segura J.J., Llamas R., Manzanaris A.J., Planas A.J., Guerrero J.M. and Calvo J.R.: Calcium hydroxide inhibits substrate adhesion capacity of macrophages. J. Endod., 1997, 444-7.

7. Sazak H., Gunday M. and Alatli C.: Effect of calcium hydroxide and combinations of ledermix and calcium hydroxide on inflamed pulp of dogs teeth. J. Endod., 1996, 447-9.

8. Andreasen J.O., Farik B. and Munksgaard E.C. Long-term calcium hydroxide as a root canal dressing may increase risk of root fracture. Dent. Traumatol. 2002, 134-7.
9. Grigoratos D., Knowles J. and Gulabivala K.: Effect of exposing dentine to sodium hypochlorite and calcium hydroxide on its flexural strength and elastic modulus. Int. Endod. J. 2001, 113-9.

10. Sogukpinar A. and Arikan V. Comparative evaluation of four endodontic biomaterials and calcium hydroxide regarding their effect on fracture resistance of simulated immature teeth. Euro. J. Ped. Dent. 2020, 23-28. 